\title{
LEVANTAMENTO DAS MANIFESTAÇÕES PATOLÓGICAS COM APLICAÇÃO DO GUT: ESTUDO DE CASO NO MERCADO CENTRAL DE CAXIAS-MA.
}

\author{
SURVEY OF PATHOLOGICAL MANIFESTATIONS WITH GUT APPLICATION: CASE STUDY IN \\ CAXIAS-MA CENTRAL MARKET.
}

\author{
PORTO COSTA, KAREN EMANUELLE \\ Graduanda do curso de Engenharia Civil \\ UniFacema \\ Maranhão; Brasil \\ karen.emanuelle01@gmail.com
}

\author{
VIDRIH FERREIRA, CLÁUDIO \\ Doutor em Geotecnia \\ UniFacema \\ Maranhão; Brasil \\ vidrih@vidrih.com.br
}

\author{
ALVES DOS R. SANTOS, PAULO RICARDO \\ Professor Especialista em Engenharia Civil \\ UniFacema \\ Maranhão; Brasil \\ pauloricardo.ars@gmail.com
}

\author{
ALVES SILVA, ANDRÉ MCLELRY \\ Graduando do curso de Engenharia Civil \\ UniFacema \\ Maranhão; Brasil \\ andremclelry10@gmail.com
}

\section{RESUMO}

O local utilizado para realização do trabalho é uma importante estrutura histórica e comercial da cidade de Caxias - MA, o Mercado Central. Notou-se um grande número de manifestações patológicas no local, associadas, muitas vezes, a execução inadequada, a falta de planejamento e a falta de manutenção preventiva adequada, o que acaba deteriorando a vida útil da edificação. Sabe-se, infelizmente, que esta é uma realidade que assola não só ao Mercado Central de Caxias - MA, como praticamente todas as obras públicas do país. Diante deste cenário, foi realizada uma inspeção visual na referida edificação, e por meio disso identificou-se os principais tipos de manifestações patológicas que a afetam, estabelecendo um grau de prioridade através da aplicação do método GUT (Gravidade, Urgência e Tendência). Utilizando ferramentas como: trena manual, fissurômetro, escalímetro, para realização de medições necessárias e câmera fotográfica. Foram constatadas descascamento de pintura; desplacamento de emboço e piso cerâmico; fissura, trinca e rachadura; mofo, bolor e fungos; das instalações hidrossanitária e elétrica; corrosão; infiltração; e afundamento. O elemento que apresentou maior quantidade de patologias fora o descascamento da pintura, e a manifestação patológica com maior grau de priorização foram fissuras, tricas e rachaduras. Observou-se assim, que uma manifestação patológica pode ocasionar danos tanto na parte estética da edificação, quanto em sua segurança estrutural, necessitando da realização de inspeções mais aprofundadas, para a proposição de medidas mitigadoras tecnicamente capazes de controlar os efeitos dos defeitos constatados, a fim de dilatar a vida útil da edificação.

Palavras-chave: manifestações patológicas, método GUT, edificação.

\section{ABSTRACT}

The place used for the work is an important historical and commercial structure of the city of Caxias - MA, the Central Market. A large number of pathological manifestations on site were noted, often associated with inadequate execution, lack of planning and lack of proper preventive maintenance, which ultimately deteriorates the useful life of the building. Unfortunately, it is known that this is a reality that plagues not only the Central Market of Caxias - MA, but practically all public works in the country. In view of this scenario, a visual inspection of the building was performed, thereby identifying the main types of pathological manifestations that affect it, establishing a degree of priority through the application of the GUT method (Gravity, Urgency and Tendency). Using tools such as manual measuring tape, fissurometer, scalimeter to perform necessary measurements and camera. Paint peeling was found; plaster peeling and ceramic flooring; crack, crack and crack; mold, mold and fungi; water and sanitary facilities; corrosion; infiltration; and sinking. The element that presented the highest amount of pathologies was the paint peeling, and the pathological manifestation with the highest degree of prioritization were fissures, tricles and cracks. Thus, it was observed that a pathological manifestation can cause damage to both the aesthetic part of the building, as well as its structural safety, requiring further inspections to propose mitigating measures technically capable of controlling the effects of the defects found. in order to extend the useful life of the building.

Keywords: pathological manifestations, GUT method, edification. 


\section{INTRODUÇÃO}

O número de obras no Brasil vem crescendo em razão das melhorias na economia do país. Contudo, em decorrência de problemas políticos e má gestão dos recursos públicos, há uma insatisfação por parte da população, no que se refere a obras públicas mal executadas e de caráter qualitativo duvidoso, traduzidos pelo rápido aparecimento de problemas, até mesmo, ainda na fase de execução.

Esses problemas, na área da engenharia, são estudados pela "Patologia das Construções", que é uma ciência a qual objetiva estudar as origens, causas, mecanismos de ocorrência, manifestações e consequências dos problemas que afetam a edificação e sua vida útil (VIEIRA, 2016). Conforme Silva (2011), o termo Patologia, de origem grega (páthos, doença, e lógos, estudo) é muito aplicado nas inúmeras áreas da ciência, com denominações do objeto de estudo que mudam conforme o ramo de atividade. Outra definição trata a patologia das estruturas como o estudo das origens, formas de manifestação, consequências e mecanismos de ocorrência das falhas e dos sistemas de degradação das estruturas (SOUZA; RIPPER, 2009).

A ciência, denominada de patologia, delimita-se ao diagnóstico dos danos nas construções, elaborando um estudo sistemático dos acontecimentos e suas causas. Diante da não realização de manutenções periódicas em obras públicas, foi realizado um estudo das manifestações patológicas presentes no Mercado Central de Caxias-MA, foram levantadas suas possíveis causas, para a condução de um diagnóstico preciso dos defeitos, estabelecendo assim uma ordem de priorização de intervenção através do método da matriz de Gravidade, Urgência e Tendência (GUT), usado para avaliar em que condições se encontra a edificação inspecionada e assim fornecer dados para nortear uma possível intervenção por parte dos órgãos responsáveis.

Apesar dos grandes avanços na indústria da construção, ainda é possível identificar muitas falhas na execução das mais diversas obras. Inúmeros são os problemas analisados nas construções, os quais poderiam ter sido evitados com a aplicação de conhecimentos mais amplos sobre as propriedades dos materiais, dos processos e das técnicas de construção (HEERDT, 2016).

O estudo sobre manifestações patológicas é de extrema relevância para saber a origem e a causa dos danos na construção, ou seja, de onde manifestou-se a doença e desta forma providenciar as medidas cabíveis de recuperação.O objetivo deste trabalho foi caracterizar e priorizar as manifestações patológicas identificadas no Mercado Central de Caxias-MA aplicando o Método da Matriz de Gravidade, Urgência e Tendência (GUT).

O Método GUT foi criado por Kepner e Tregoe em 1980, a partir da necessidade de resolução de problemas complexos nas indústrias americanas e japonesas. Muitos obstáculos podem aparecer em uma organização, e nem sempre é possível resolvê-los simultaneamente (KEPNER; TREGOE, 1981). Considerando a importância do cenário em que agem as manifestações patológicas e que se intensificam principalmente em obras públicas, será usado o método GUT (Gravidade, Urgência e Tendência) como principal ferramenta de forma a apontar as falhas na edificação e estabelecer a ordem crescente de prioridades.

\section{MATERIAIS E MÉTODOS}

\subsection{Objeto de estudo}

O local utilizado para realização do trabalho é de certa forma uma importante estrutura histórica e comercial da cidade de Caxias-MA, a quinta mais populosa cidade do estado, com população de 164.224 habitantes, conforme dados do IBGE de 2018. É um dos maiores centros econômicos graças a seu grande desempenho industrial e um importante centro político, econômico e populacional (IBGE, 2018).

A edificação em análise foi o Mercado Central José Ferreira de Castro, em Caxias-MA. Reinaugurado em 2009, construído em uma área de $10 \mathrm{mil} \mathrm{m}^{2}$, o qual contém 600 boxes, abrigando mais de 600 feirantes. A Figura 01 ilustra a fachada da referida edificação. 
Figura 01- Fachada principal do Mercado Central.

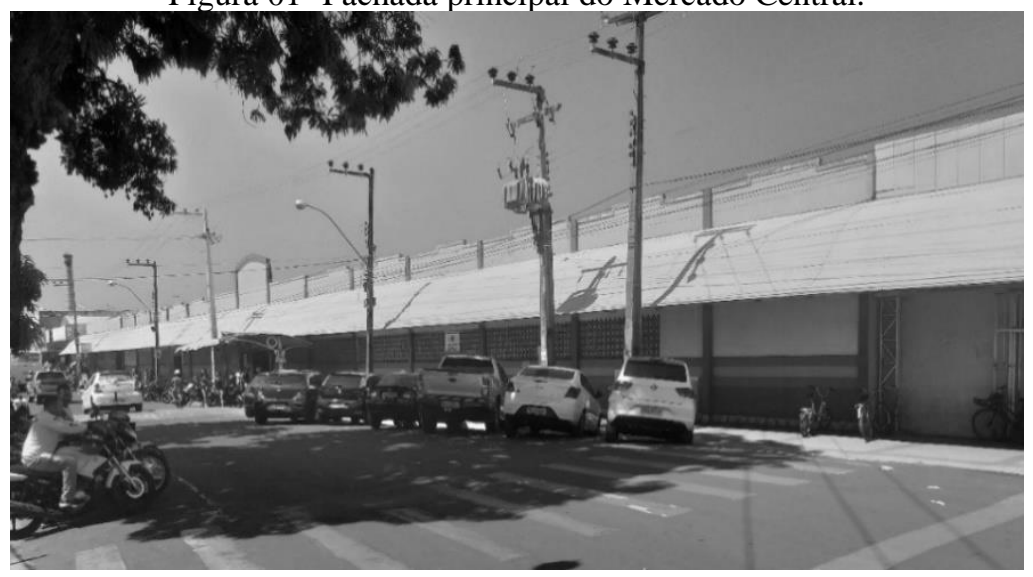

Fonte: Autor (2019).

\subsection{Equipamentos utilizados}

Para realizar o levantamento das manifestações foram necessários alguns equipamentos básicos que pudessem auxiliar neste processo. Assim foram utilizados:

- 01 trena manual,

- 01 prancheta,

- 02 canetas esferográficas,

- 01 escalímetro, e

- 01 câmera fotográfica.

Desta forma, foram identificados e registrados os defeitos em evidência na edificação inspecionada, buscando analisá-los e assim indicar as possíveis causas que possam ter desencadeado o aparecimento das mesmas, assim como estabelecer um grau de prioridade de intervenção como base no método GUT.

\subsection{Tratamento e análise dos dados}

Esta pesquisa trata-se de um estudo de caso e levou em consideração a situação da obra pública, visando a identificação das manifestações patológicas presentes. Foi utilizado um checklist para identificar e quantificar as patologias que fossem sendo detectadas no decorrer da inspeção feita no Mercado Central.

Para fornecer a estrutura teórica, a fim de realizar as análises e observações pertinentes de forma coerente, foi utilizado artigos, dissertações, livros e normas que tratem do assunto explanado, demostrando a importância do tema e as manifestações típicas referentes ao material avaliado. Além disso, realizou-se uma análise bibliográfica sobre a Matriz GUT, a fim de se apropriar dos conceitos e critérios (conforme o Quadro 01) levados em conta pelo método, sendo este utilizado para fazer o processo de tratamento e análise dos dados colhidos. Da mesma forma foi utilizada a técnica não destrutiva de inspeção visual para as avaliações das características visuais em função da presença de manifestações patológicas, coletando dados e registros fotográficos das mesmas.

Os dados aqui encontrados, serão apresentados e discutidos na seção seguinte desta pesquisa.

\begin{tabular}{clll} 
Nota & \multicolumn{2}{c}{$\begin{array}{c}\text { Quadro 01: Matriz de prioridade. } \\
\text { Gravidade }\end{array}$} & \multicolumn{1}{c}{$\begin{array}{c}\text { Urgência } \\
\text { Tendência } \\
\text { ("se nada for feito...") }\end{array}$} \\
\hline $\mathbf{5}$ & extremamente grave & precisa de ação imediata & ...irá piorar rapidamente \\
\hline $\mathbf{4}$ & muito grave & é urgente & ...irá piorar em pouco tempo \\
$\mathbf{3}$ & grave & o mais rápido possível & ...irá piorar \\
$\mathbf{2}$ & pouco grave & pouco urgente & ...irá piorar a longo prazo \\
$\mathbf{1}$ & sem gravidade & pode esperar & ...não irá mudar \\
\hline \multicolumn{5}{r}{} & Fonte: Periard (2011). & \\
\end{tabular}




\section{RESULTADOS E DISCUSSÃO}

Durante a inspeção visual realizada no Mercado Central de Caxias-MA, foram constatados vários tipos de manifestações patológicas. Após isso, os resultados foram agrupados de acordo com os principais tipos de anomalias encontradas em: descascamento de pintura; desplacamento de emboço e piso cerâmico; fissura, trinca e rachadura; mofo, bolor e fungos; das instalações hidrossanitária e elétrica; corrosão; infiltração; e afundamento, as quais serão descritas a seguir.

Através da inspeção realizada, possível encontrar patologias em 334 pontos diferentes, de formas e dimensões variadas. $\mathrm{O}$ resultado é mostrado na Tabela 01, apresentando assim a quantidade e a porcentagem de cada anomalia em ordem crescente de incidência.

Tabela 01: Frequência por tipo de manifestação patológica.

\begin{tabular}{|c|c|c|}
\hline Tipo & Quantidade & Porcentagem \\
\hline Descascamento da pintura & 98 & $29,34 \%$ \\
\hline Desplacamento (piso cerâmico e emboço) & 50 & $14,97 \%$ \\
\hline Fissuras, trincas e rachaduras & 50 & $14,97 \%$ \\
\hline Mofo, bolor e fungos & 32 & $9,58 \%$ \\
\hline Hidrossanitária & 17 & $5,09 \%$ \\
\hline Corrosão & 70 & $20,96 \%$ \\
\hline Elétrica & 13 & $3,89 \%$ \\
\hline Infiltração & 02 & $0,60 \%$ \\
\hline Afundamento & 02 & $0,60 \%$ \\
\hline Total & 334 & $100 \%$ \\
\hline
\end{tabular}

Fonte: Autor (2019).

A seguir serão apresentados os registros fotográficos realizados de cada tipo de manifestação patológica detectada, e a partir das quais foram realizados as análises e o estabelecimento do grau de prioridade para cada tipo de anomalia através da aplicação do método GUT.

\subsection{Descascamento da pintura}

Segundo Polito (2006), a descamação é a ruptura na pintura provocada pelo atrito natural do tempo, comprometendo a superfície. No início o problema é apresentado como uma fina fissura, depois surgem as descamações da tinta. Isso pode ocorrer devido a aplicação de tinta de baixa qualidade, que apresenta pouca adesão e flexibilidade, a grande diluição da tinta, a preparação não adequada da superfície e alta fragilização de tinta alquídica antiga.

Como se pode observar, o tipo de anomalia com maior incidência na edificação inspecionada foi o descascamento da pintura, encontrado em 98 pontos distintos, correspondendo a 29,34\%, ocupando assim a primeira posição. 
Figura 02 - Descascamento da pintura.

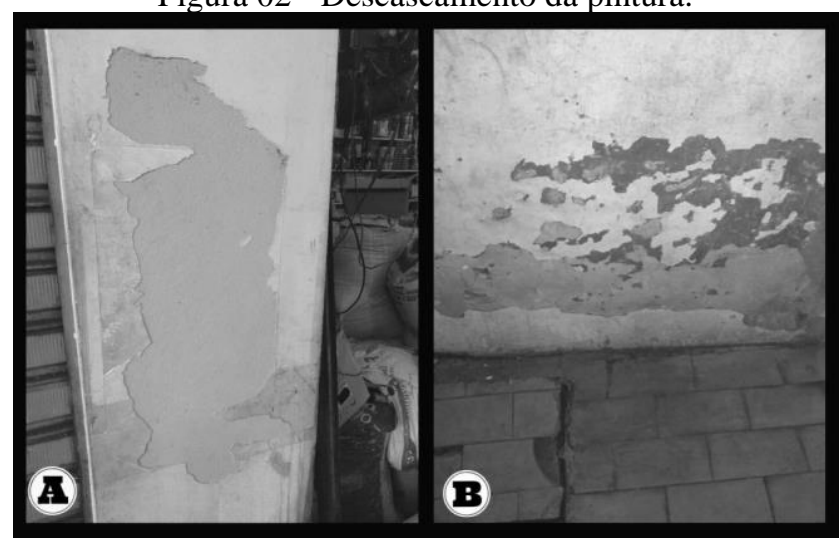

Fonte: Autor (2019).

\subsection{Desplacamento (piso cerâmico e emboço)}

Consoante a NBR 13816 (1997), o revestimento cerâmico é composto por placas cerâmicas, argamassa de assentamento e rejunte. Já as placas cerâmicas para revestimento são compostas por argila e outras matérias primas inorgânicas normalmente usadas para revestir pisos e paredes, sendo conformadas por extrusão, por prensagem, ou ainda por outros processos.

A perda de aderência é uma ocorrência causada por erros ou rupturas na interface da cerâmica com a argamassa adesiva, da mesma forma desta com o substrato, devido a tensões surgidas que excedam a capacidade resistente das ligações (CAMPANTE; SABBATINI, 1999). Por se localizarem na parte externa da edificação as placas cerâmicas estão sujeitas a grandes variações de temperatura, umidade e outros agentes intempéricos, ocasionando os descolamentos das placas cerâmicas na fachada do prédio, como mostra na Figura 03. O desplacamento (piso cerâmico e emboço) foi encontrado em 50 pontos distintos, correspondendo a 14,97\% das manifestações patológicas que assolam a edificação.

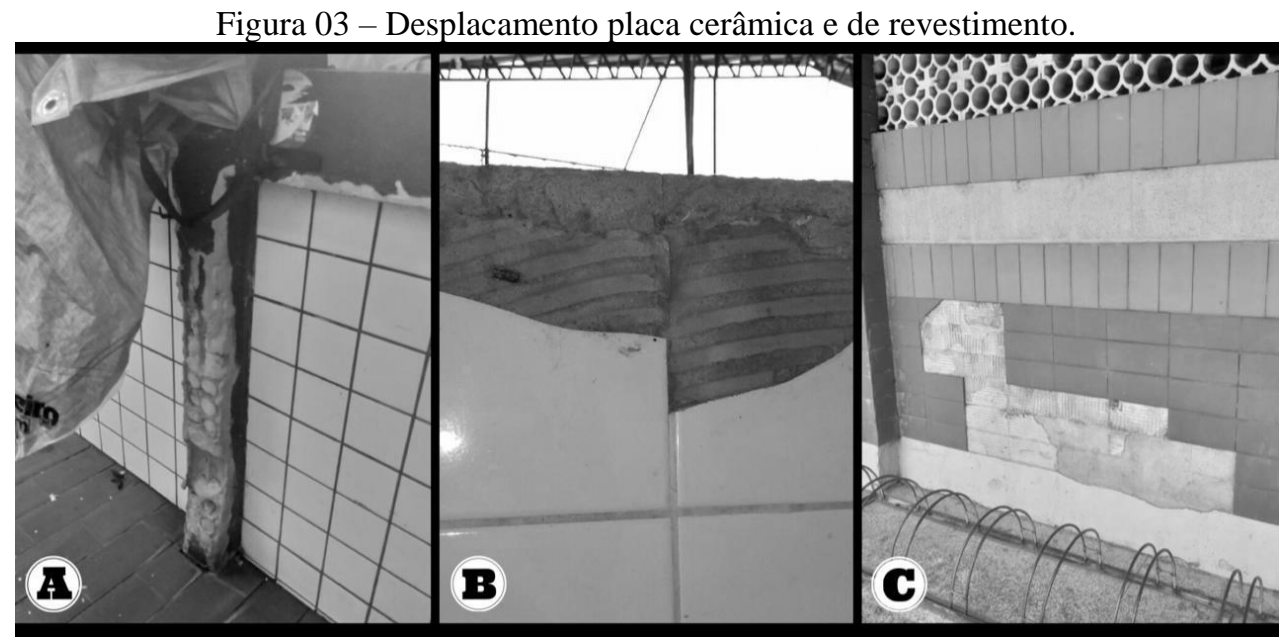

Fonte: Autor (2019).

\subsection{Fissuras, trincas e rachaduras}

Segundo Santos (2002), o surgimento de fissuras está, normalmente, relacionado a processos químicos, ainda que condições físicas e mecânicas também possam estar incluídas, em acordo ou não, com os processos químicos. As reações químicas são transmitidas através de impactos físicos nocivos, tais como o aumento da porosidade e permeabilidade, redução da resistência, fissuração e destacamento do concreto. Uma outra alternativa refere-se à ocorrência de recalque na fundação e da sobrecarga de esforços nas vigas e pilares. 
A fissura se define como uma fenda na superfície, com pequena profundidade e estreita. Da mesma forma, a trinca é como uma fenda um tanto considerável e de certa profundidade, classificada entre a fissura e a rachadura. E a rachadura é uma abertura significamente relevante e desmedida que compromete parcial ou totalmente um componente construtivo (IBAPE - SP, 2002).

Este tipo de manifestação patológica foi constatado no interior do Mercado Central de Caxias-MA, conforme ilustrado na Figura 04. As fissuras, trincas e rachaduras foram encontradas em 50 pontos distintos, correspondendo a $14,97 \%$ das manifestações patológicas identificadas.

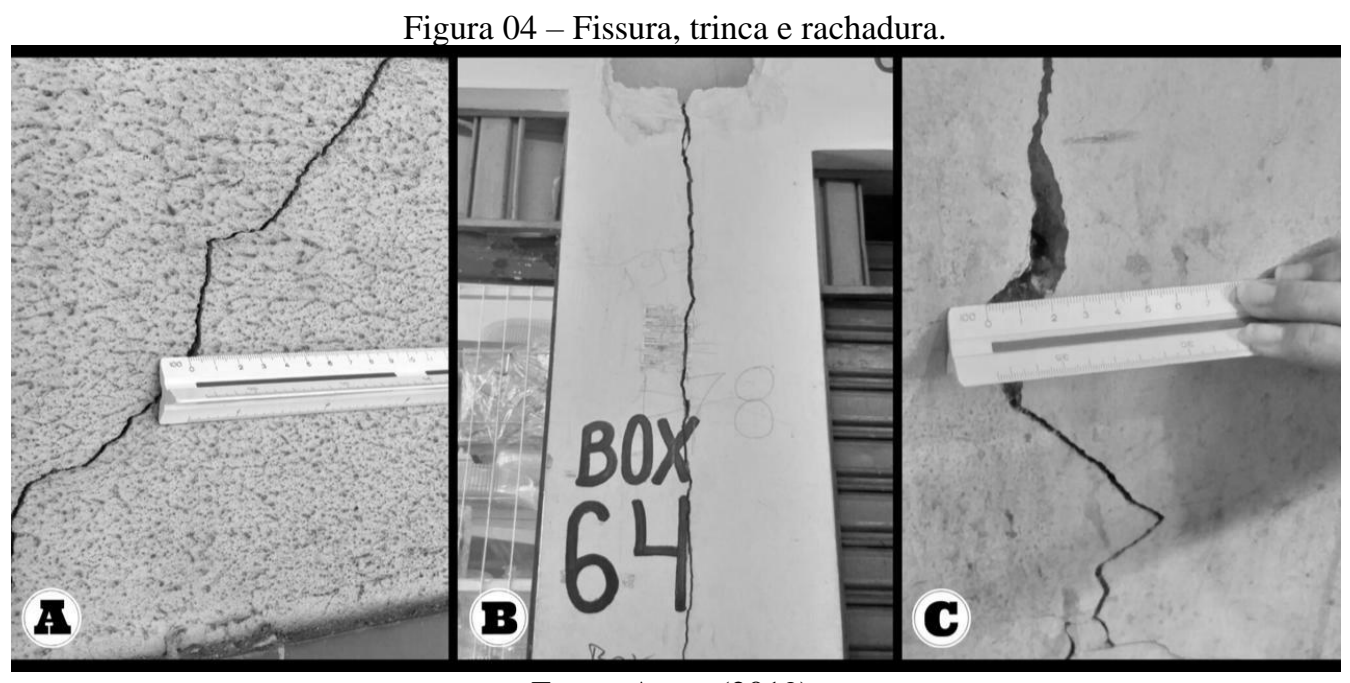

Fonte: Autor (2019).

\subsection{Mofo, bolor e fungos}

De acordo com Guerra (2012), a ação de fungos filamentosos, é o fator determinante para a evolução do bolor nas superfícies das alvenarias da edificação, porque esses microrganismos são aeróbicos e decompositores da matéria orgânica.

Esse tipo de manifestação foi encontrado em 32 locais diferentes, principalmente em paredes da área externa do ambiente, isso acontece devido a umidade encontrada nas mesmas. A Figura 05 mostra o estado encontrado no mercado em estudo.

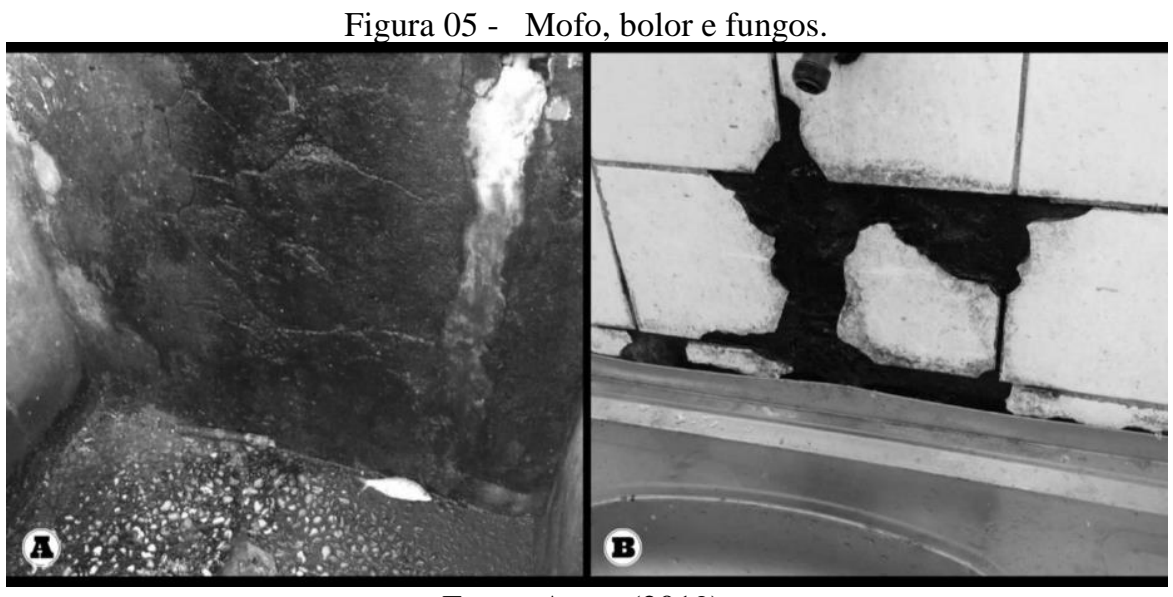

Fonte: Autor (2019).

\subsection{Hidrossanitária}

Existe uma grande variedade de materiais do sistema predial hidráulico como: bombas hidráulicas, tubos, registros, válvulas, conexões, tanque. Essa variedade favorece o aparecimento das manifestações patológicas nas 
instalações hidráulicas, que vão de simples erros até defeitos mais graves e que comprometem o aspecto funcional da edificação. Grande parte destas manifestações são causadas devido a erros no projeto, como o dimensionamento hidráulico, ausência de especificação de materiais e detalhes construtivos (GNIPPER; MIKALDO JUNIOR, 2005).

Em relação a presença de manifestações patológicas em instalações hidrossanitárias, foram identificados 17 pontos que continham algum tipo de anomalia associado a esse tipo de instalação predial, o equivalente a 5,09\%. A degradação ocorre por várias razões, como: tubulações de PVC expostas à ação de intempéries, falta de manutenção e limpeza dos aparelhos sanitários.

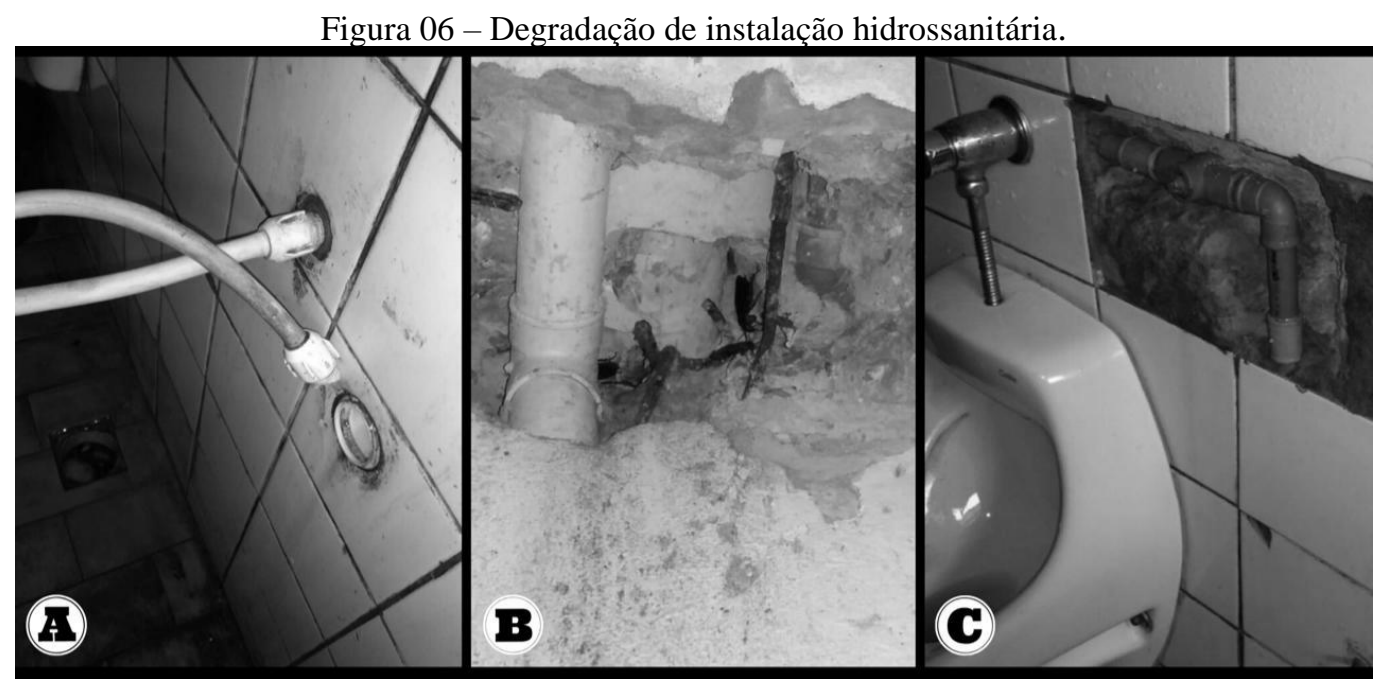

Fonte: Autor (2019).

\subsection{Corrosão}

A corrosão é causada pela ação do meio sobre um determinado material, esse processo gera a deterioração. A primeira associação que se faz é com a ferrugem, em que sua camada de cor marrom-avermelhada se forma em superfícies metálicas. Os prejuízos causados atingem muitos gastos, resultando em consideráveis desperdícios de investimento, acidentes e perdas de vidas humanas ocasionados por contaminações, poluição e falta de segurança dos equipamentos (MERÇON; GUIMARÃES; MAINIER, 2004).

O cobrimento indevido da armadura ajuda a reação de oxidação. A umidade e o ar são outros fatores fundamentais para ocorrer a corrosão. No estudo foi detectado corrosão em 70 pontos distintos, correspondendo a $20,96 \%$.

Figura 07 - Corrosão em estrutura metálica e em armadura de pilar.

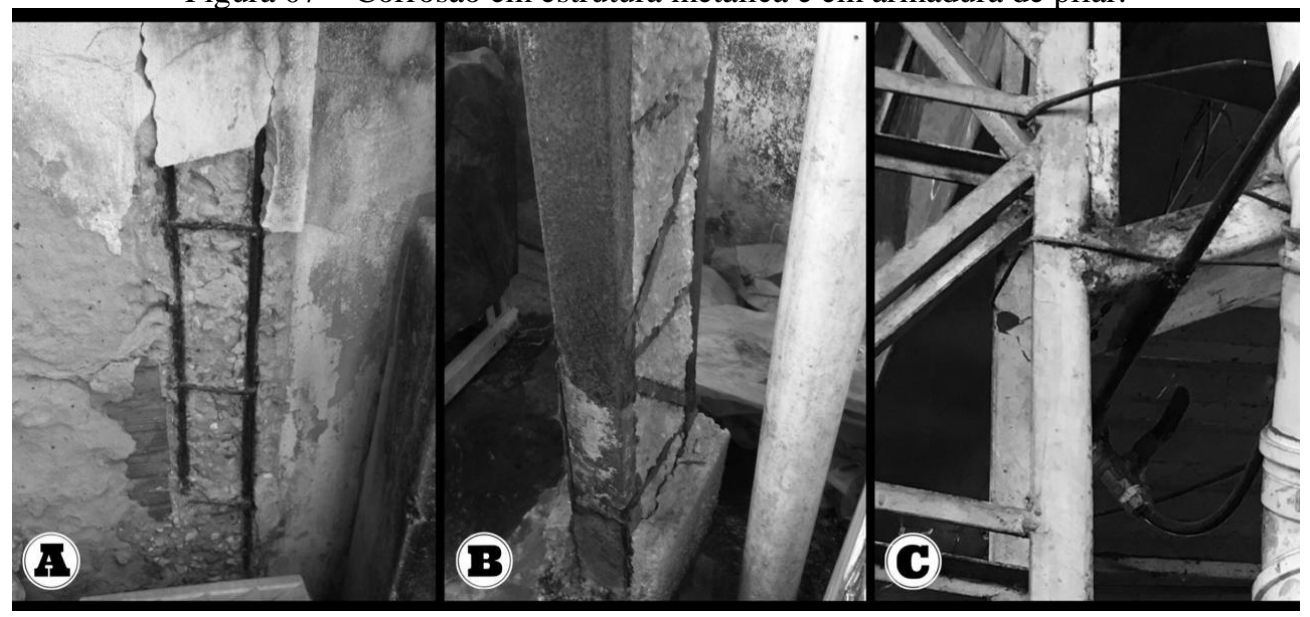

Fonte: Autor (2019). 


\subsection{Instalações elétricas}

Consoante a NBR 5410 (ABNT, 2004), devem-se avaliar a frequência e a qualidade da manutenção com que a instalação pode ter, ao longo de sua vida útil, de modo que a manutenção e os reparos indispensáveis possam ser realizados de forma segura e simples, a efetividade das medidas de proteção fique certa e a confiabilidade dos componentes, em relação ao funcionamento preciso da instalação, seja compatível com a vida útil prevista desta.

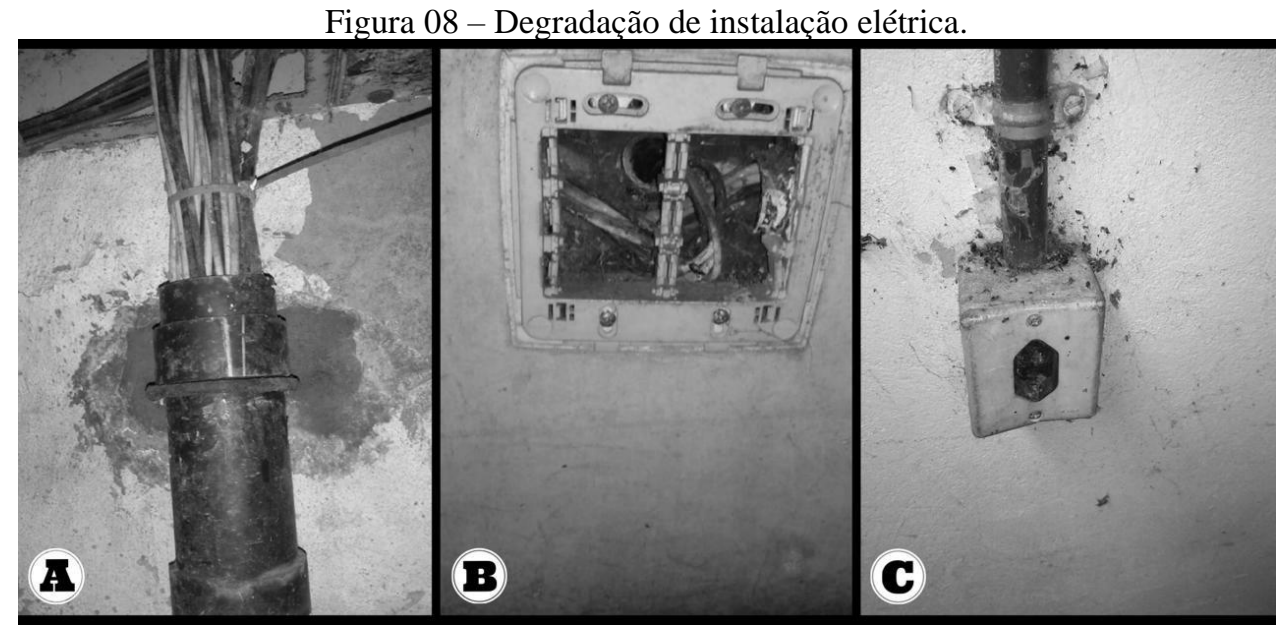

Fonte: Autor (2019).

A fiação foi encontrada exposta e sem isolação adequada. Além disso, os pontos de tomada e os interruptores estavam em situação precária, e sem condições de utilização, o que acaba gerando um grande risco de acidente para os funcionários do local, assim como para os próprios visitantes. A Figura 08 retrata essas irregularidades.

\subsection{Infiltração}

As condições de higiene que provocam um incômodo pessoal aos proprietários de uma edificação, além de contribuir para a degeneração da mesma, estão cada vez mais presentes nas edificações, isso acontece por causa da grande existência de infiltrações provocada pelas mais diversas razões, como: falhas de instalações, acidentes ou falta de manutenção, particularidade da natureza em relação a localização ou devido aos erros e defeitos de construção (CECHINEL, 2011). Esse tipo de defeito foi encontrado em 02 pontos diferentes da edificação vistoriada, correspondendo a $0,60 \%$, como mostra na Figura 09.

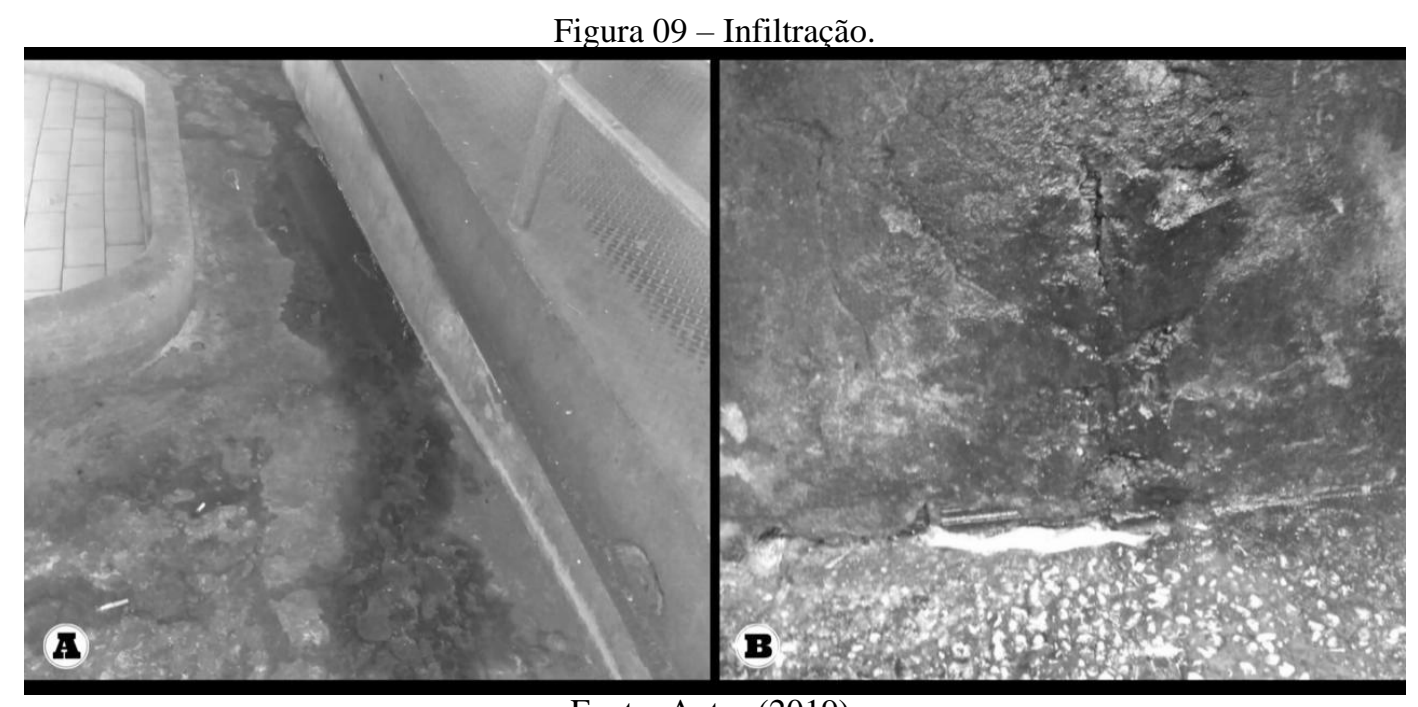

Fonte: Autor (2019). 


\subsection{Afundamento}

Conforme Riva, Polachini, Orlandini e Maschio (2018), o afundamento em piso em “paver” na passagem, está associado a má compactação da camada de base do piso. Recomenda-se recompactar a camada de base do piso, removendo as peças e nivelando o solo, compactando-o corretamente e após isso, o reassentamento dos blocos, garantindo o intertravamento entre os pavers. Observou-se o afundamento do piso em 02 locais distintos, correspondendo a 0,60\%, conforme ilustra a Figura 10.

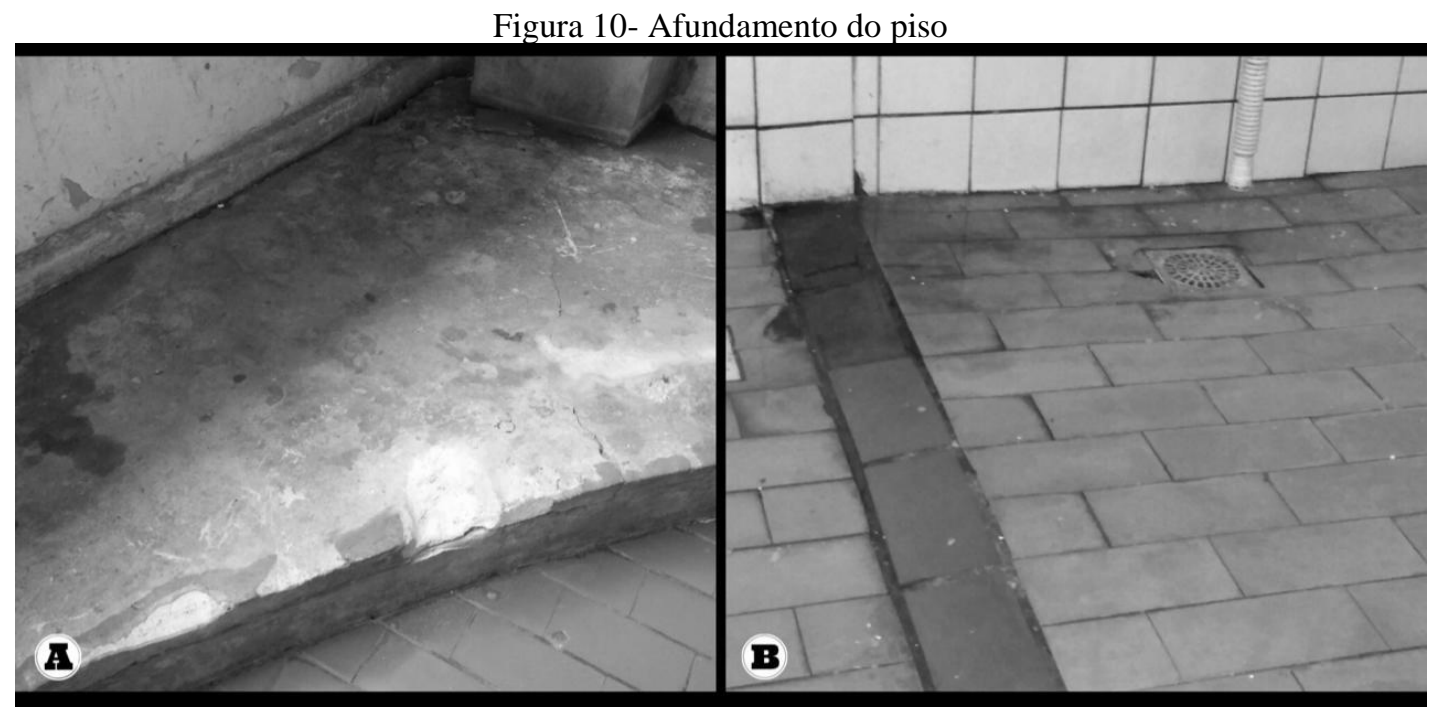

Fonte: Autor (2019).

\subsection{Aplicação do método GUT}

Depois da apresentação das manifestações mostradas, partiremos para aplicação do método GUT, para saber a gravidade, urgência e tendência de cada manifestação patológica de modo a estabelecer um grau de prioridade de intervenção das mesmas. Os critérios utilizados para classificar as anomalias, foram os expostos no Quadro 01, realizandose o preenchimento da matriz conforme a inspeção realizada no local. A Tabela 02, apresenta as manifestações patológicas identificadas no estudo de caso de acordo com as variáveis do método GUT.

Tabela 02 - Matriz de aplicação pelo método GUT

\begin{tabular}{|l|c|c|c|c|c|}
\hline Manifestação patológica & G & $\mathbf{U}$ & $\mathbf{T}$ & GUT & $\begin{array}{c}\text { Grau de } \\
\text { priorização }\end{array}$ \\
\hline Descascamento da pintura & 2 & 1 & 2 & 4 & $7^{\circ}$ \\
\hline $\begin{array}{l}\text { Desplacamento (piso } \\
\text { cerâmico emboço) }\end{array}$ & 3 & 2 & 3 & 18 & $4^{\circ}$ \\
\hline $\begin{array}{l}\text { Fissuras, trincas e } \\
\text { rachaduras }\end{array}$ & 4 & 3 & 4 & 48 & $1^{\mathbf{o}}$ \\
\hline Mofo, bolor e fungos & 3 & 3 & 3 & 27 & $3^{\circ}$ \\
\hline Hidrossanitária & 2 & 2 & 2 & 8 & $5^{\circ}$ \\
\hline Corrosão & 3 & 3 & 4 & 36 & $2^{\mathbf{o}}$ \\
\hline Elétrica & 2 & 2 & 2 & 8 & $5^{\mathbf{o}}$ \\
\hline Infiltração & 2 & 1 & 2 & 4 & $7^{\circ}$ \\
\hline Afundamento & 2 & 1 & 3 & 6 & $6^{\circ}$ \\
\hline
\end{tabular}

Fonte: Autor (2019).

A Tabela 03 dispõe de forma crescente a ordem de prioridade para possíveis intervenções nas manifestações patológicas avaliadas. Com base nos dados acima, pode-se notar que, mesmo não sendo em maior quantidade, a manifestação patológica com maior grau de prioridade, após a aplicação da matriz, foram as fissuras, trincas e rachaduras, 
encontradas em elementos estruturais como: pilares e vigas, as quais podem comprometer a capacidade portante da estrutura.

Tabela 03 - Ordem de prioridade para reparo das manifestações

\begin{tabular}{|c|c|}
\hline Grau de priorização & Manifestação patológica \\
\hline $1^{\mathbf{o}}$ & Fissuras, trincas e rachaduras \\
\hline $2^{\mathbf{o}}$ & Corrosão \\
\hline $3^{\mathbf{o}}$ & Mofo, bolor e fungos \\
\hline $4^{\circ}$ & Desplacamento (piso cerâmico e emboço) \\
\hline $5^{\mathbf{o}}$ & Elétrica \\
\hline $6^{\circ}$ & Afundamento \\
\hline $7^{\circ}$ & Descascamento da pintura \\
& Infiltração \\
\hline
\end{tabular}

Fonte: Autor (2019).

\section{CONCLUSÕES}

Após a realização da vistoria no Mercado Central de Caxias-MA, verificou-se que as manifestações patológicas apresentadas pela edificação, lhe causam um certo dano relacionado, principalmente, aos aspectos estéticos, devido a presença de manchas, desgaste do revestimento de algumas paredes, além de destacamento das placas cerâmicas da fachada, bem como funcionais, relacionados a existência de trincas em alguns elementos estruturais (vigas e pilares) da edificação, o que pode comprometer a capacidade portante da estrutura da edificação.

Com o método GUT, ferramenta que ajuda na priorização de tarefas para solucionar problemas, foi possível priorizar as patologias com base na concepção da gravidade delas, na urgência e na tendência, se vai piorar de lenta a rapidamente, e assim tratá-las na ordem correta. Seus benefícios são: diminuição de custos, melhor utilização do tempo, melhor administração, impactos negativos menores e maiores oportunidades.

Após a aplicação dos critérios estabelecidos pela matriz constatou-se que a manifestação patologica de maior recorrência na edificação são as Fissuras, Trincas e Rachadura, o que remete a uma necessidade de intervenção prioritária a esse tipo de patologia, já que muitas das vezes estão associadas a problemas estruturais. Porém, só poderão ser apontadas as causas reais para as anomalias suparcitadas, bem como medidas técnicas que venham a mitigar estes problemas, atráves de um diagnóstico seguramente firmado, principalmente quando se trata das trincas e as fissuras constatadas em algumas vigas e pilares da edificação.

A pesquisa propiciou dados que podem ser utilizados para nortear manutenções ou intervenções futuras na edificação, tendo em vista melhorias nos seus aspectos funcionais, aumentando assim sua vida útil e garantindo segurança e conforto aos seus usuários e também ajudando como sugestão a trabalhos futuros. 


\section{REFERÊNCIAS}

ABNT NBR 13816 - Placas cerâmicas para revestimento - Terminologia. Rio de Janeiro, 1997.

ASSOCIAÇÃO BRASILEIRA DE NORMAS TÉCNICAS. NBR 5410: Instalações elétricas de baixa tensão. Rio de Janeiro, segunda edição ed. 2004. 209 p. Disponível em:

<https://hosting.iar.unicamp.br/lab/luz/ld/normas\%20e\%20relat\%f3rios/NRs/nbr_5410.pdf>. Acesso em: 9 nov. 2019.

CAMPANTE, E. F.; SABBATINI, F. H. Durabilidade de revestimentos cerâmicos de fachada. Congresso Iberoamericano de Patologia de lãs Construcciones, V, CONPAT, Montevideo, 1999. Anais. Montevideo. p. 183-191.

CECHINEL, B. M.; VIEIRA, F. L, MANTELLI, P.; TONEL, S. Infiltração Em Alvenaria: Estudo De Caso Em Edifício Na Grande Florianópolis. Caderno De Publicações Acadêmicas. Instituto Federal de Educação, Ciência e Tecnologia de Santa Catarina - IF-SC. Florianópolis/SC, 2011.

GNIPPER, S. F.; MIKALDO JUNIOR, J. Patologias frequentes em sistemas prediais hidráulicos - sanitários e de gás decorrentes a falhas decorrentes de falhas no processo de produção do projeto. Disponível em: <http://www.toget. com.br/clientes/ajeci/artigos/Artigo-29\%20Patologias\%20frequentes\%20em\%20 SPHS\%20decorrentes\%20de\%20falhas\%20nosprojetos.pdf>. Acesso em: 20 out. 2019.

GOOGLE MAPS. Mercado Central Caxias-MA, Brasil. Disponível em: <https://www.google.com/maps/place/Mercado+Central+do+Municipio/@-4.861184,43.3704506,1478m/data=!3m1!1e3!4m8!1 m2!2m1!1smercado+central+caxias+ma!3m4!1s0x78e922c4c324c9b:0xe142 f30171a9ac4c! $8 \mathrm{~m} 2$ !3d-4.8599551!4d-43.3650219?hl=pt-BR>.

GUERRA, F. L.; CUNHA, E. G. da; SILVA, A. C. S. B. da; KNOP, S. Análise das condições favoráveis à formação de bolor em edificação histórica de Pelotas, RS, Brasil. Ambiente Construído, Porto Alegre, v. 12, n. 4, p. 7-23, out./dez. 2012.

HEERDT, G. B. Principais patologias na construção civil. Academia, 2016. Disponível em: <https://www.academia.edu/31785497/principais_patologias_na_construção_civil>. Acesso em: 10 abr. 2019.

IBAPE-SP. Glossário De Terminologia Básica Aplicável à Engenharia de Avaliações e Perícias do Ibape/Sp, 2002.

IBGE - Instituto Brasileiro de Geografia e Estatística. Censo Demográfico 2018.

KEPNER, C. H.; TREGOE, B. B. O administrador racional. São Paulo: Atlas, 1981.

MERÇON, F.; GUIMARÃES, P. I. C.; MAINIER, F. B. Corrosão: Um exemplo usual de fenômeno químico. Química Nova na Escola, Rio de Janeiro, v. 19, p.11-14, maio 2004. Disponível em: <qnesc.sbq.org.br/online/qnesc19/a04.pdf>. Acesso em: 09 nov. 2019.

PERIARD, G. Matriz GUT: Guia Completo, 2011. Disponível em: <http://www. sobreadministracao.com/matriz-gutguia-completo/>. Acesso em: 12 abr. 2019.

POLITO, G. Principais Sistemas de Pinturas e suas Patologias. Escola de Engenharia. Depto. de Engenharia de Materiais e Construção, mar. 2006. Disponível em: www.demc.ufmg.br/tec3/Apostila\%20de\%20pintura\%20$\% 20$ Giulliano\%20Polito.pdf. Acesso em: 28 out. 2019.

RIVA, D. J.; POLACHINI, G.; ORLANDINI, L. C; MASCHIO, D. M. da R. Estudo de caso: Presença de patologias em residência unifamiliar em alvenaria. Congresso Técnico Científico da Engenharia e da Agronomia Contecc'2018, Maceió - Al, 21 ago. 2018. Disponível em: <www.confea.org.br/sites/default/files/antigos/contecc2018/civil/121_edcpdperuea.pdf>. Acesso em: 10 nov. 2019.

SANTOS, A. Trincas, fissuras, fendas e rachaduras exigem cuidado. IBDA. 2002. Disponível em: <http://www.forumdaconstrucao.com.br/conteudo.php?a=17\&Cod=1579>. Acesso em: 12 abr. 2019.

SILVA, F.B. Patologia das construções: uma especialidade na engenharia civil. Téchne - A Revista do Engenheiro Civil, São Paulo, ano 19, n. 174, p. 72-77, setembro 2011. 


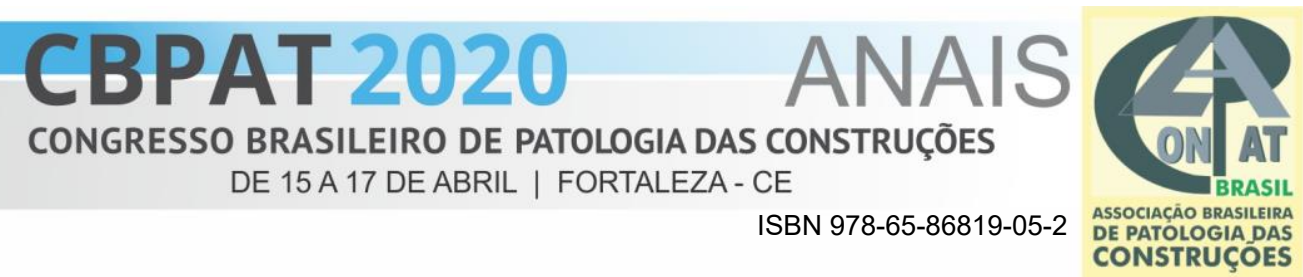

SOUZA, V.C.M.; RIPPER, T. Patologia, recuperação e reforço de estruturas de concreto. 1a ed. São Paulo: Pini Ltda, 2009.

VIEIRA, M. A. Patologias Construtivas: conceito, Origens e Método de Tratamento. Revista Especialize On-Line IPOG. Goiânia, 12a ed, n. 012, jan-dez/2016. 